\title{
MEMBANGUN BINA DAMAI MELALUI SISTEM KEKERABATAN (DALIHAN NA TOLUDAN RAKUT SITELU) DI KABANJAHE KABUPATEN TANAH KARO
}

\author{
Fitriani \\ Universitas Islam Negeri Sumatera Utara (UINSU) Medan \\ fitriani@uinsu.ac.id
}

\begin{abstract}
Abstrak
Keragaman orang di Indonesia, yang terdiri dari berbagai macam suku, agama, ras dan budaya, adalah salah satu keunikan untuk bangsa ini. Begitu juga dengan kerukunan masyarakat yang didukung oleh sistem kekerabatan dalam bentuk nilai atau norma yang terkandung dalam agama dan budaya yang nantinya akan mampu membangun perdamaian dan menjaga kerukunan dalam kehidupan beragama. Penelitian kualitatif antropologis ini bertujuan untuk mengungkap kehidupan orang-orang yang secara budaya penting dapat dilihat sebagai perilaku keagamaan dalam kehidupan orang Batak di Kabanjahe yang terkait dengan pembangunan perdamaian. Temuan penelitian menunjukkan bahwa kearifan lokal digunakan sebagai alat pemersatu, harmonisasi di tengah pluralitas masyarakat karo multikultural.
\end{abstract}

Kata kunci: Bina Damai, Sistem Kekerabatan; Daliban na tolu dan Rakut Sitelu

\begin{abstract}
The diversity of people in Indonesia, which consists of various kinds of tribes, religions, races and cultures, is unique for this nation. Likenise with the harmony of the community which is supported by a kinship system in the form of values or norms contained in religion and culture which will later be able to build up peace and maintain harmony in religious life. This anthropological qualitative study aims to reveal the lives of people who are culturally essential can be seen as religious behavior in the lives of Batake people in Kabanjahe associated with peace-building. The research findings show that local wisdom is used as a unifying tool, harmonization in the midst of a plurality of multicultural karo societies.
\end{abstract}

Keywords: Daliban na tolu, Kinship System; Peace Building, Rakut Sitelu

\section{Pendahuluan}

Pluralitas agama di era globalisasi menjadi karakteristik dari bangsa Indonesia yang heterogen. Sehingga tidak dapat dipungkiri, pluralitas agama memiliki potensi dan peran sangat besar dalam proses integrasi dan pembangunan. Selain itu pluralitas agama juga mampu menciptakan dunia konflik dan disintegrasi bangsa. Untuk itu pentingya peran kehadiran budaya yang berupa system kekerabatan menjadi jembatan membangun masyarakat yang harmonis dan damai dalam kehidupan masyarakat yang multikultural. 
Melihat dinamika keberagamaan masyarakat senantiasa selalu memunculkan dua wajah yaitu adanya konflik dan bina-damai, demi keberlangsungan hidup bersama dan untuk menghindari potensi konflik maka dibutuhkan proses bina-damai guna menjaga keharmonisan. Ada beberapa bentuk bina-damai berupa sistem kekerabatan yang dijadikan sampel agar terwujudnya masyarakat yang harmonis. Salah satu diantaranya sistem kekerabatan Dalihan na Tolu, yang dijadikan pedoman bahkan sebagai falsafah hidup masyarakat Batak, terutama Batak Toba dan Mandailing. Tidak hanya masyarakat Batak Mandailing yang memiliki sistem kekerabatan, selain itu masyarakat Batak Karo juga memiliki sistem kekerabatan yang disebut Rakut Sitelu. Yang menjadi keunikan penelitian ini adalah kedua sistem kekerabatan yang dijadikan sampel tersebut memiliki konsep nilai yang sama, yaitu sistem kekerabatan yang sama-sama memiliki konsep nilai pemersatu dan menjadi mekanisme untuk membangun bina-damai dalam keberagamaan masyarakat Batak di Tanah Karo.

Menelisik kekerabatan orang batak, kita sebaiknya mengetahui makna dan hakikat dari kekerabatan tersebut. Kekerabatan adalah menyangkut hubungan hukum antar orang dalam pergaulan hidup. Orang Batak memperhitungkan hubungan keturunan itu secara patrilineal. Suatu kelompok kekerabatan itu dihitung dengan satu ayah, satu kakek atau satu nenek moyang. Perhitungan hubungan berdasarkan satu ayah disebut Sada Bapa pada masyarakat Batak Karo dan Saama pada orang Mandailing. Perhitungan hubungan berdasarkan satu kakek atau satu nenek moyang disebut Sada Nini pada masyarakat Batak Karo dan Saompu pada orang Mandailing.

Ada dua bentuk kekerabatan bagi suku Batak, yakni berdasarkan garis keturunan (genealogi) dan berdasarkan sosiologis. Bentuk kekerabatan berdasarkan garis keturunan (genealogi) terlihat dari silsilah marga mulai dari Si Raja Batak, dimana semua suku bangsa Batak memiliki marga. Sedangkan kekerabatan berdasarkan sosiologis terjadi melalui perjanjian (antar marga tertentu) maupun karena perkawinan. Dalam tradisi Batak, yang menjadi kesatuan adat adalah ikatan sedarah dalam marga. Adat Batak atau tradisi Batak sifatnya dinamis yang seringkali disesuaikan dengan waktu dan tempat yang sangat berpengaruh terhadap perbedaan corak tradisi antar daerah.

Levi-Strauss menyatakan bahwa dalam masyarakat bersahaja biasanya didominasi oleh sistem kekerabatan dan masyarakatnya berinteraksi di dalamnya berdasarkan sistem simbolik yang menentukan sikap mereka terhadap paling sedikit tiga kelas kerabat, yaitu kerabat karena hubungan darah, karena hubungan perkawinan dan karena hubungan keturunan. Suatu sistem budaya sering berupa pandangan hidup (word view) bagi manusia yang menganutnya. Pandangan hidup biasanya mengandung sebagian dari nilai-nilai yang dianut oleh suatu masyarakat, yang dipilih secara selektif oleh para individu dan golongan-golongan dalam masyarakat. 
Pada hakikatnya, upaya untuk menghidupkan budaya lokal adalah suatu sisi dari penerapan semangat multikulturalisme. Mengkaji kearifan lokal bukan berarti penyeragaman (monolistik), tetapi sebagai hasil kreativitas sebagai warga budaya untuk menggali dan mengoptimalkan potensi budayanya. Menggali dan mengoptimalkan local genious juga berarti memberdayakan kearifan budaya lokal, baik yang berupa sistem nilai, sistem sosial, maupun aspek budaya fisik.

Apabila masyarakat masih didominasi aturan adat, maka masyarakatnya akan teratur dengan sendirinya. Simbol-simbol dan identitas lain menjadi lenyap di dalam struktur adat. Kepatuhan terhadap adat, sistem kekerabatan dan tradisi leluhur lainnya menyebabkan pemahaman dan praktek keagamaan beradaptasi dengan nilai-nilai yang ada pada masyarakat setempat. Sebagaimana disebutkan Bruner, bahwa keharmonisan masyarakat yang disebabkan ketakutan kelompok minoritas atas kekuatan mayoritas, namun di Kecamatan Kabanjahe, Kabupaten Karo hal ini lebih ditujukan kepada kepatuhan terhadap sistem daripada kekuatan massif. Oleh karena itu ada mekanisme keseimbangan lain yakni terjadinya eliminasi rasa superioritas terhadap minoritas karena adanya pranata masyarakat Karo yang dikenal Rakut Sitelu dan pada masyarakat Mandailing dikenal Dalihan na Tolu.

\section{Dalihan na Tolu}

Untuk membangun bina-damai dalam masyarakat Batak Mandailing di Tanah Karo, maka masyarakat Batak Mandailing menawarkan konsep atau falsafah hidup dalam membangun binadamai dan menjaga kerukunan yang disebut dengan Dalihan na Tolu. Daliban na Tolu secara etimologi diartikan sebagai tungku yang penyangganya terdiri dari tiga, agar tungku tersebut dapat seimbang. Sedangkan secara terminologi merupakan satu lembaga adat kemasyarakatan yang merupakan satu kesatuan dari kahanggi, mora, dan anak boru.

Kahanggi diartikan sebagai teman semarga yang laki-laki, baik yang kandung maupun yang berkerabat dekat, mora adalah keluarga dari pihak ibu, sedangkan anak boru adalah keluarga dari pihak ayah. Kedudukan mora dalam Dalihan na Tolu menempati posisi yang paling tinggi, oleh karena itu pihak mora selalu dikatakan sebagai pangidoan tua (tempat meminta pendapat yang baik), atau sering dijadikan sebagai mediator dalam penyelesaian permasalahan (konflik). Dengan demikian, ketiga unsur Daliban na Tolu merupakan kekuatan yang besar dalam kehidupan bermasyarakat terutama dalam hal siriaon (pesta perkawinan) dan pesta adat lainnya termasuk juga dalam masalah kesedihan karena ditimpa musibah seperti siluluton (kematian). Begitu halnya, Dalihan na Tolu juga diartikan sebagai sendi yang paling pokok dari kehidupan orang Batak. Tidak satupun kegiatan orang Batak yang dapat lepas dari sendi ini, kecuali bagi mereka yang sama sekali sudah melepaskan diri ikatan ini. 
Sebab Dalihan na Tolu adalah dasar falsafah hidup orang Batak Mandailing dan menjadi pondasi susunan masyarakat. Adanya aturan dan sanksi yang telah menjadi kesepakatan (konsensus) leluhur tentang pranata Daliban na Tolu, memungkinkan tercapainya hubungan yang erat (kohesi) antar masyarakat dan kelanjutan kebudayaannya.

Inti ajaran Dalihan na Tolu adalah kaidah moral berisi ajaran saling menghormati (marsipasangapon) dengan dukungan kaidah moral: saling menghargai dan menolong. Dalihan na Tolu menjadi media yang memuat azas hukum yang objektif. Begitu halnya, di dalam pelaksanaan upacara adat ketiga unsur Daliban na Tolu harus tetap dalam mardomu ni tahi (selalu mengadakan musyawarah mufakat). Musyawarah dan mufakat akan tercapai apabila unsur Dalihan na Tolu;

Pertama, memiliki rasa persatuan dan kesatuan, rasa persatuan dan kesatuan adalah merupakan salah satu faktor yang harus dijunjung tinggi di dalam lembaga Daliban na Tolu. Sejalan dengan rasa kesatuan dan persatuan yang dalam melakukan setiap pekerjaan harus dimuswarahkan bersama, dikerjakan bersama, maka hasilnya juga adalah hasil bersama. Dengan demikian jika hasilnya atas usaha bersama, maka akan timbul pula perasaan bahwa hasilnya tersebut merupakan milik bersama harus dinikmati bersama. Perasaan memiliki ini kemudian akan menimbulkan dorongan kepada masing-masing untuk memelihara miliknya tersebut. Kedua, memiliki rasa tanggung jawab, rasa tanggung jawab bersama ini yang terutama harus dilaksanakan oleh unsur lembaga Daliban na Tolu, dengan sendirinya muncul sebagai akibat adanya rasa persatuan dan kesatuan serta rasa memiliki. Rasa tanggung jawab ditimbulkan oleh rasa bahwa beban orang lain adalah beban bersama, kegagalan orang lain adalah kegagalan bersama, keberhasilan orang lain adalah keberhasilan bersama. Maksudnya adalah dalam bermasyarakat setiap kahanggi, mora, maupun anak boru itu sama-sama mempunyai tanggung jawab. Dan dalam bermusyawarah tidak saling berselisih pendapat.

Dalam adat Dalihan na Tolu sistem kekerabatan tersebut memberikan aturan-aturan bagi setiap elemen untuk menjadi masyarakat terbuka, kosmopolit serta tidak membedakan manusia karena suku, agama dan asal-usul. Namun status seseorang hanya ditentukan oleh kedudukannya dalam pranata tersebut.

Pada hakikatnya, kekerabatan merupakan inti utama budaya masyarakat Batak, sistem kekerabatan masyarakat Batak Mandailing sendiri tersimpul dalam Dalihan na Tolu. Hubungan kelompok sosial dalam sistem kekerabatan ini membentuk pola-pola relasi sosial, baik tutur sapa maupun struktur sosial dalam adat. Adat Dalihan na Tolu terbentuk dengan adanya hubungan margamarga. Dalihan na Tolu untuk mengatur partuturon dan mekanisme interaksi antar marga (clan) di suatu kampung. Dari luasnya hubungan kekerabatan dalam adat Batak maka dapat dilihat tumbuhnya 
harosuan (keakraban) dan nilai ini sangat mendasar dalam segala pergaulan. Nilai kekerabatan itu tidak sekedar teori, tapi diaplikasikan dalam bentuk mekanisme sosial adat Dalihan na Tolu sampai sekarang.

Sistem adat yang menjadi konsensus dalam masyarakat Batak disebabkan oleh adanya kekuatan primordial Dalihan na Tolu dan Rakut Sitelu sebagai mekanisme pengatur hubungan sesama masyarakat Batak dan etnik lain, atau diantara mereka yang berbeda agama. Sebagaimana disebutkan dalam kitab suci al-Qur'an dalam beberapa ayat menyinggung masalah kemajemukan surat $\mathrm{Al}$ Hujurat (49) ayat 13 yang berbunyi :

"Hai manusia, sesungguhnya Kami menciptakan kamu dari seorang laki-laki dan seorang perempuan dan menjadikan kamu berbangsa-bangsa dan bersuku-suku supaya kamu saling kenal-mengenal. Sesunggubnya orang yang paling mulia di antara kamu di sisi Allah ialah orang yang paling taqwa di antara kamu.Sesunggubnya Allah Maha Mengetabui lagi Maha Mengenal."

Gagasan tentang kedamaian dan kerukunan yang dikedepankan alqur'an itu telah dipraktekkan Nabi Muhammad Saw. dalam masyarakat Madinah, sebagaimana tergambar dalam berbagai pasal Piagam Madinah. Nabi Muhammad Saw mendaratkan gagasan itu secara tulus dan jujur. Dari sumber yang lain :

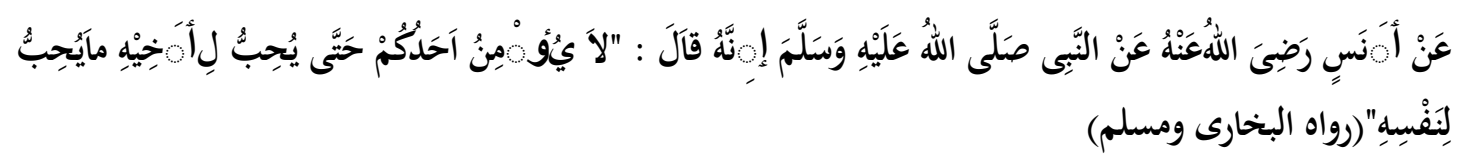

Dari Anas r.a. babwa sesunggubnya Rasulullah Saw. bersabda, "Tiada sempurna iman seorang kamu bingga dia mencintai saudaranya sebagaimana dia mencintai dirinya sendiri."(HR Bukhari dan Muslim)

Hadis di atas menjelaskan bahwa setiap manusia harus saling mencintai di antara sesama manusia, bersaudara dan saling menghargai. Dengan demikian, suasana kehidupan yang harmonis akan tetap terjaga. Begitu juga halnya, seperti yang dijelaskan dalam agama Kristen Protestan dalam Matius 22:39 "Berbuat baik terbadap sesama untuk saling mengasibi atas dasar kasih sebab adalah menjadi kewajiban sesama manusia seperti kata-Nya, kasibilah sesamamu manusia seperti mengasibi dirimu sendiri."

Begitulah keharmonisan antara manusia penganut agama yang berbeda, gagasan yang didasarkan pada kenyataan adanya akar harmonitas di antara agama-agama tersebut.

\section{Rakut Sitelu}

Persfektif tentang masyarakat tidaklah lengkap tanpa melihat sistem kekerabatannya. Interaksi sosial merupakan hubungan sosial yang dinamis antar perorangan, antar kelompok dan antar perorangan dengan kelompok. Dalam hubungan sosial itu terjadi hubungan yang saling mempengaruhi, mengubah, memperbaiki kelakuan di antara individu dan kelompok. Tidak hanya 
masyarakat Mandailing yang memiliki sistem kekerabatan, masyarakat Karo juga memiliki system kekerabatan yang dinamakan Rakut Sitelu.

Secara etimologiRakut berarti ikatan sedangkan Sitelu berarti tiga, dengan demikian Rakut Sitelu berarti ikatan yang tiga. Rakut sitelu memiliki arti setiap individu Karo tidak lepas dari keluarganya. Namun, ada pula yang mengartikannya sebagai sangkep nggelub (kelengkapan hidup). Rakut sitelu kadang juga disebut daliken sitelu. Secara etimologis, daliken sitelu berarti tungku yang tiga (Daliken: batu tungku, Sitelu: tiga). Makna dari daliken sitelu menunjuk pada kenyataan bahwa untuk menjalankan kehidupan sehari-hari, masyarakat Batak Karo tidak lepas dari yang namanya tungku untuk menyalakan api (memasak).

Sementara itu, unsur dan pembentuk Rakut Sitelu tersebut adalah: Kalimbubu, yang diartikan sebagai keluarga dari pihak ibu. Sembuyak atau Senina. Dimaknai sama dengan kahanggi adalah teman semarga yang laki-laki, baik yang kandung maupun yang berkerabat dekat. Sementara anak beru adalah keluarga dari pihak ayah. Kedudukan Kalimbubu dalam Rakut Sitelu menempati posisi yang paling tinggi, oleh karena itu pihak Kalimbubu sebagai pemberi perempuan dan sangat dihormati dalam sistem kekerabatan masyarakat Batak Karo. Masyarakat Batak Karo meyakini bahwa Kalimbubu adalah pembawa berkat. Sikap menentang dan menyakiti hati kalimbubu sangat dicela dan tidak diperkenankan. Dalam hal memberi nasihat, semua nasihat yang diberikan kalimbubu dalam suatu musyawarah keluarga menjadi masukan yang harus dihormati dan dihargai. Sama halnya seperti kedudukan Mora dalam Daliban na Tolu.

Selanjutnya adalah Anak beru adalah pihak pengambil perempuan atau penerima perempuan untuk diperistri. Anak beru disebut pula hakim moral, karena bila terjadi perselisihan dalam keluarga kalimbubu-nya, tugasnyalah mendamaikan perselisihan tersebut. Sementara itu, senina adalah hubungan kekerabatan berdasarkan marga yang sama, tugas senina adalah memimpin pembicaraan dalam musyawarah danberperan sebagai sekat dalam pembicaraan adat agar tidak terjadi friksi-friksi ketika akan memusyawarahkan pekerjaan yang akan didelegasikan kepada anak beru.

Kajian ini sangat unik dan menarik yang dapat kita ketahui akan kekayaan kultur masyarakat di Indonesia, ternyata memiliki kesamaan nilai budaya yang menjunjung tinggi persatuan dan kedamaian berupa system kekerabatan sebagai wadah dalam mewujudkan bina-damai di dalam masyarakat yang multicultural dan multireligius. Seperti kita lihat masyarakat Mandailing di Kabanjahe, Kabupaten Tanah Karo sebagai host culture terhadap Dalihan na Tolu yang merupakan pandangan hidup dan mengatur tata kehidupan adat, sosial dan agama. Terutama yang akan 
ditampilkan disini adalah hubungan Batak Mandailing sebagai pendatang yang beragama Islam terhadap Batak Karo yang penguhuni asli yang mayoritas pemeluk agama Kristen.

Hal ini dianggap penting karena disharmonis terjadi acapkali disebabkan oleh tidak adanya atau ketidakmampuan perangkat budaya dalam mengatur kebhinekaan di masyarakat, terkadang disebabkan oleh munculnya rasa superioritas penduduk asli terhadap imigran luar maupun kurangnya pola adaptasi dari penduduk perantau tersebut.

Dalam hasil temuan ini, masyarakat Karo sebagai penduduk asli sangat terbuka terhadap siapa saja yang datang dan ingin menjalin hubungan terhadapnya tanpa mempersoalkan agama, budaya dan etnis lainnya. Sebab dimensi agama, budaya maupun etnis tidak menjadi patokan kedudukan seseorang dalam bermasyarakat. Sementara masyarakat Mandailing sebagai pendatang mampu berinteraksi dan membentuk pola adaptasi dengan baik terhadap penduduk asli Tanah Karo, bahkan menurut pemaparan seorang tokoh adat dari Mandailing bapak Maradong Siregar, bahwa masyarakat Mandailing ini sangat berpegaruh besar terhadap perkembangan Islam di Tanah Karo, terutama di Kecamatan Kabanjahe. Alasannya karena orang Mandailing memiliki sikap yang bijak untuk beradpatasi dengan baik dalam menyesuaikan adat, budaya dan karakter pada masyarakat Batak Karo.

\section{Dialog Pemersatu; Merdang Merdem}

Dialog merupakan salah satu cara untuk saling berkomunikasi, baik personal maupun komunal. Sebuah dialog yang bermakna tulus dan memperkaya semua pihak yang terlibat di dalam dialog, mengandaikan adanya suatu bentuk kedekatan, keterbukaan, saling percaya dan saling menghargai satu sama lain, terutama menghargai perbedaan yang ada pada masing-masing pihak, serta adanya kesediaan untuk saling berbagi. Menurut A. Mukti Ali untuk menciptakan kondisi yang kondusif di tengah masyarakat yang majemuk, baik agama, budaya, bahasa dan lain sebagainya maka diperlukan adanya konsep Agree in Disagramet (setuju dalam perbedaan).

Dialog harus diakui sebagai cara yang paling penting untuk membudayakan kehidupan rukun dan harmonis diantara seluruh umat beragama. Agama harus dihayati dalam semangat dialog, baik dialog antara individu dengan Tuhannya maupun dialog antar-sesama manusia. Pentingnya dialog sebagai sarana untuk mencapai kedamaian, sebab banyak konflik maka banyak terjadi sikap anarkis. Dialog yang tulus dan terarah kiranya dapat membantu dalam menghadapi masalah-masalah yang berkaitan dengan kehidupan beragama. Hanya dengan sebuah dialog yang sehat dan dewasa dapat mencapai kesepakatan untuk membentuk kerjasama atas nama agama. 
Berbagai cara yang dilakukan untuk mempersatukan masyarakat, setiap daerah tentu mempunyai cara yang berbeda untuk mencapai tujuan bersama. Pada masyarakat Batak di Kabanjahe untuk membangun bina-damai dan menjaga keharmonisan, melakukan bentuk dialog yang berupa kegiatan atau dialog aksi. Dialog aksi ini bertujuan agar masyarakat dapat berkumpul atau secara tidak langsung menjalin komunikasi antara yang satu dan lainnya. Dalam hal ini masyarakat Batak di Kabanjahe, Tanah Karo melakukan dialog dalam bentuk pesta tahunan atau dikenal dengan merdang merdem. Merdang merdem merupakan bentuk refleksi kepercayaan dalam Suku Karo di Sumatera Utara sebagai bagian dari masyarakat agraris nusantara. Pesta tahunan (merdang merdem) adalah sebuah ritual atau upacara penyembahan kepada Sang Pencipta. Tujuannya agar setiap aktivitas pertanian yang dilakukan bisa menghasilkan panen yang berlimpah berupa doa-doa yang dipanjatkan kepada Sang Pencipta agar tanaman padi diberkati, bebas dari hama dan menghasilkan panen yang berlimpah.

Merdang merdem tersebut merupakan salah satu bentuk dialog aksi yang terjadi dalam kehidupan masyarakat Batak di Kabanjahe, baik dalam hal pekerjaan, kegiatan sosial atau keagamaan dapat memberikan suasana yang positif. Dialog aksi tersebut berupa kegiatan, seperti kerjasama dalam segala aktifitas kehidupan sehari-hari. Masyarakat Batak Mandailing di Kabanjahe dari berbagai agama maupun budaya melakukan gotong royong baik berdasarkan hubungan tetangga ataupun hubungan kekerabatan. Aktivitas kerjasama anatar sejumlah besar masyarakat bertujuan untuk menyelesaikan suatu proyek tertentu yang dianggap kepentingan umum.

Integrasi budaya dan agama yang terjadi pada masyarakat Batak di Tanah Karo yang menjadi temuan di lapangan sebagai aplikasi dari nilai-nilai yang ada dalam masyarakat Batak Mandailing dan Batak Karo. Dari penelitian ini, ditemukan kegiatan adat yang telah dibungkus simbol-simbol agama seperti halnya pesta kelahiran, pernikahan maupun kematian. Meskipun berbeda prosesi keagamaan dalam segmen tertentu masing-masing pemeluk agama turut terlibat dalam acara adat tersebut. Acara adat merupakan rangkaian yang tidak terpisahkan dari unsur-unsur keagamaan.

Sebab adat selalu diyakini memiliki dimensi religiusitas tersendiri berdasarkan warisan leluhur. Saat ini warna agama sudah semakin dominan dalam setiap kegiatan adat. Selain kegiatan adat, terdapat saling mengundang dan memberikan bantuan terhadap satu sama lain, serta memberi kata sambutan pada ritual keagamaan baik dalam acara kelahiran, pernikahan maupun kematian. Terutama dalam acara kematian, partisipasi lintas agama sangat tinggi bagi kalangan masyarakat Batak di Kecamatan Kabanjahe, Kabupaten Karo. 


\section{Kesimpulan}

Berdasarkan pemaparan dan pembahasan dan analisis yang dilakukan, maka dapat ditarik simpulan bahwa di tengah intensitas interaksi masyarakat yang multikultur dan multireligius dalam konteks era globalisasi saat ini, masyarakat sangat membutuhkan sebuah konsensus atau kesepakatan bersama berupa nilai maupun norma baik dari budaya maupun agama yang akan dijalankan bersama untuk menghadapi tantangan hidup secara bersama-sama. Demi keberlangsungan hidup bersama dan untuk menghindari potensi konflik maka masyarakat Batak di Tanah Karo perlu menghadirkan proses bina-damai berupa system kekerabatan yang akan mengatur kehidupan masyarakat dalam tatanan kerukunan .

Bentuk bina-damai yang dilakukan masyarakat Batak Mandailing di Kecamatan Kabanjahe, Kabupaten Tanah Karo ialah berdasarkan system kekerabatan yaitu Dalihan na Tolu, yang menjadi keunikannya adalah tidak hanya masyarakat Batak Mandailing yang memiliki sistem kekerabatan, Batak Karo juga memiliki sistem kekerabatan yang disebut Rakut Sitelu. Menurut hasil penelitian penulis pada masyarakat Kecamatan Kabanjahe baik dari hasil observasi maupun wawancara dapat diambil kesimpulan bahwa Dalihan na Tolu maupun Rakut Sitelu memberikan kontribusi dalam membangun bina-damai dan menguatkan kerukunan antar umat beragama di Kecamatan Kabanjahe. Kedua sistem kekerabatan ini memiliki konsep nilai yang sama, sistem kekerabatan tersebut akan menjadi mekanisme untuk membangun bina-damai dalam keberagamaan masyarakat Mandailing di Kecamatan Kabanjahe, Kabupaten Tanah Karo.

Ada beberapa saran yang direkomendasikan dalam laporan hasil penelitian ini, yaitu: (1). Studi tentang konflik keagamaan tidak dapat dipisahkan atau akan lebih baik tidak memisahkan dengan studi bina-damai dalam sebuah penelitian mengenai konflik, karena kedua hal tersebut yaitu konflik dan bina-damai bergerak dan berjalan seirama, hanya bentuk dominan dari keduanya yang berbeda. (2). Manajemen keberagamaan seperti masyarakat Batak di Kecamatan Kabanjahe, Kabupaten Karo harus tetap dilakukan dengan pendekatan "sensivitas budaya" dimana budaya menjadi alat perekat dan pemersatu perbedaan agama. (3). Penelitian ini bisa menjadi acuan bagi daerah etnik lain: yakni perlunya menggali tradisi masyarakat yang memuat aturan-aturan hubungan masyarakat yang heterogen, dan untuk pemerintahannya perlu memberdayakan peranan adat untuk mengikat masyarakat agar tetap bersatu, dinamis dan seimbang. 
Membangun Bina Damai Melalui Sistem Kekerabatan (Dalihan Na Tolu dan Rakut Sitelu)

di Kabanjahe Kabupaten Tanah Karo

\section{Daftar Pustaka}

Abdullah, M. Amin,"Rekonstruksi Metodologi Studi Agama dalam Masyarakat Multikultural dan

Multirelijius" dalam M. Amin Abdullah, dkk., (ed.), Antologi Studi Islam: Teori dan Metodologi, Yogyakarta: Sunan Kalijaga Press, 2000.

Abdullah, Taufik, Sejarah Lokal di Indonesia, Yogyakarta: Gajah Mada University Press, 1990.

Abu-Nimer, Mohammad, Nirkekerasan dan Bina-Damai dalam Islam, Teori dan Praktik, terj. Rizal Panggabean \& Ihsan Ali-Fauzi, Jakarta: alvabet \& yayasan wakaf Paramadina, 2010.

Aritonang, S. Jan, dkk., Beberapa Pemikiran Menuju Dalihan Natolu, Jakarta: Dian Utama, 2006.

Doangsa, Dalihan Natolu sistem Sosial Kemasyarakatn Batak Toba, Jakarta : KERABAT, 2007.

Elmirzana, Syafa'atun, Pluralisme, Konflik dan Perdamaian; Studi Bersama Antar Iman, Yogyakarta: Interfide, 2002.

Galtung, Johan, Studi Perdamaian: Perdamaian dan Konflik, Pembangunanan Peradaban, terj. Asnawi dan Safruddin, Surabaya: Pustaka Eureka, 2003.

Geertz, Clifford, Kebudayaan dan Agama, Yogyakarta: Kanisius, 1992.

Ginting, M. Ukur, Adat Karo Sirulo; Tuntumnan Praktis Adat Istiadat Karo, Medan: Lembaga Persada Karo, 2012.

Hidayah, Irfatul, Agama dan Budaya Lokal: Peran Agama dalam Proses Marginalisasi Budaya Lokal, dalam jurnal Religi volume 2, Nomor 03, 2003.

Nasution, Farizal, Jejak Sejarah dan Budaya Karo, Medan: MITRA, 2012.

Pedersen, Batak Blood and Protestant Soul, The Development of National Batak Churches in North Sumatra, Michigan: William B. Eerdmans Publishing Company, 1970.

R. Stark dan C.Y. Glock, Dimensi-dimensi Keberagamaan dalam Agama; dalam Analisa dan Interpretasi Sosiologis, Jakarta: Raja Grafindo Persada, 1993.

Zada, Khamami, dkk., Prakarsa Perdamaian, Pengalaman dari Berbagai Konflik Sosial , Jakarta: PP Lakpesdam NU, 2008. 